\title{
Echinococcus granulosus strain typing in Bulgaria: the G1 genotype is predominant in intermediate and definitive wild hosts
}

Received: 1 March 2004 / Accepted: 10 March 2004/Published online: 1 May 2004

(C) Springer-Verlag 2004

\begin{abstract}
Addressing the genetic variability in Echinococcus granulosus is epidemiologically important, as strain characteristics may influence the local transmission patterns of zoonotic cystic echinococcosis. To classify the genotype(s) present in intermediate (pig, cattle and sheep) and definitive (jackal and wolf) hosts in Bulgaria, a DNA-based approach was used to assess parasite protoscoleces or strobiles. Genes corresponding to coding and non-coding regions of the nuclear and mitochondrial genome ( $N D$-1, $H B X$, Act II, $A g B-1$ ) were amplified by PCR and subsequently sequenced. The sequences resolved were all found to be identical to those published for the common sheep strain of E. granulosus, indicating that the $G 1$ genotype is predominant in Bulgaria. One microvariant for ND-1 was found in the pig isolates; however no epidemiological significance was attributed to this finding.
\end{abstract}

\section{Introduction}

Echinococcus granulosus is the aetiological agent of cystic echinococcosis (CE), which is an important cause of human morbidity and mortality, particularly in regions where pastoral activities are prominent. $\mathrm{CE}$ is a cosmopolitan zoonotic infection with different mammalian hosts being involved in the life cycle (McManus and Bowles 1996; Eckert et al. 2000; McManus et al.

I. Breyer · B. Gottstein $(\bowtie)$

Institute of Parasitology, University of Berne, Länggass-Strasse 122, 3012 Berne, Switzerland

E-mail: bruno.gottstein@ipa.unibe.ch

Fax: + 41-31-6312622

D. Georgieva

Veterinary Faculty, Thracian University,

Stara Zagora, Bulgaria

R. Kurdova

Department of Parasitology and Tropical Medicine,

National Center of Infectious and Parasitic Diseases,

26 Yanko Sakazov Blvd., 1504 Sofia, Bulgaria
2003). E. granulosus requires an intermediate and a definitive host to complete its life cycle. The hydatid cyst or metacestode develops predominantly in the liver and/ or lungs of intermediate hosts, maturating into protoscolex production by asexual multiplication and differentiation. This larval stage proliferation, associated with high rates of sexual self-fertilisation in adults (inbreeding), and with the natural selection exerted by the hosts' biology, may have a strong impact on the evolutionary genetic differentiation in E. granulosus. The role of sexual reproduction between adult worms (outcrossing), a basically powerful tool involved in parasite adaptation, is not yet well clarified in echinococcosis. Population genetic data indicate that outcrossing does occur, although very rarely, at least in populations with some genetic variants (Lymbery et al. 1992; Haag et al. 1998).

Currently, ten genetically distinct strains $($ Gl-G10), differing in several characteristics that may affect the host range, development rate, infectivity to humans, pathogenicity and antigenicity have been identified in E. granulosus (Thompson and Lymberry 1988; Thompson et al. 1995; Lavikainen et al. 2003). These variants were assigned to genotypes, as defined, e.g. according to mitochondrial gene sequencing (Bowles et al. 1992; Bowles and McManus 1993), restriction fragment length polymorphism of the ribosomal ITS1 fragment (Bowles and McManus 1993) and comparative analyses of DNA sequence homologies (Bowles and McManus 1993; McManus et al. 1994; Reddy et al. 1998; Lavikainen et al. 2003)

In Bulgaria, the most important factors influencing the persistence, re-emergence and spread of E. granulosus infection have recently been described by Todorov and Boeva (1999). E. granulosus infection was highly endemic during the period between 1950 and 1962, with a total of 6,469 new surgical cases of CE in humans, equivalent to an annual incidence rate of 6.5 per 100,000 people. A high parasite prevalence was recorded in dogs and livestock animals (Todorov and Boeva 1999). In the definitive wild hosts, the prevalence determined in jackals was $31 \%$ (12 out of 39 jackals shot in the Sredna 
Gora area and in the Stara Planina mountains) and 36\% in wolves (10 out of 28 wolves shot in the Sredna Gora area and in the Stara Planina mountains) (Georgieva et al. 1999a, 1999b). A control programme, initiated in 1960, led to a considerable improvement of the situation in the period between 1971 and 1982, with a decrease of the annual incidence of human CE to 2.0 per 100,000 . Owing to administrative irregularities and economic changes, funds for the control campaign were reduced and the control structures dismantled. As a result, the E. granulosus infection in humans and animals has re-emerged. Between the periods 1971-1982 and 19831995 , the proportions of infected dogs and sheep increased from $4 \%$ to $7 \%$ and from $19 \%$ to $32 \%$, respectively. During the same periods, the annual average nationwide number of surgical cases (new and readmitted) of human CE increased from 176 to 291, and the corresponding annual incidence increased from 2.0 to 3.3 per 100,000 . In 1995 , the average incidence by district showed wide variations, ranging from 1.9 to 15.8 per 100,000, with high endemicity, especially in the southern parts of the country (Todorov and Boeva 1999).

As CE represents an important public health problem in Bulgaria, molecular epidemiological insight into the situation may provide useful data contributing to appropriate control strategies. In the present work, we analysed the genetic variability of Bulgarian E. granulosus isolates of intermediate and definitive hosts by PCR and subsequent sequencing.

\section{Materials and methods}

\section{Parasites}

A total of 24 E. granulosus isolates were analysed. Twenty samples consisted of purified protoscoleces (each sample originated from a single cyst, with eight obtained from different cattle, six from sheep and six from pigs). Four other samples consisted of a few strobiles (collected from three jackal intestines and from one wolf). All samples were from different geographical locations within the larger Stara Zagora region in Bulgaria (Table 1).

Table 1 Host characteristics of the 24 isolates of Echinococcus granulosus analysed in this study

\begin{tabular}{llll}
\hline Isolate code & Parasite stage & Host & Provincial origin \\
\hline 1C-8C & Protoscolex & Cattle & Stara Zagora region \\
1S-6S & Protoscolex & Sheep & Stara Zagora region \\
1P-6P & Protoscolex & Pig & Stara Zagora region \\
1 J-3 J & Strobiles & Jackal & Sredna Gora region and \\
& Stara Planina mountains \\
1 W & Strobiles & Wolf & Sredna Gora region \\
\hline
\end{tabular}

\section{DNA extraction}

Total genomic DNA was isolated and purified from 50 $100 \mu$ of pelleted parasite material (protoscoleces or strobiles) using a DNAeasy tissue kit (QIAGEN, Switzerland). The DNA samples were subsequently stored at $-20^{\circ} \mathrm{C}$ until used for PCR.

\section{PCR and sequencing}

In order to carry out full analyses of the genomic markers, we investigated four different genes representing coding and non-coding sequences of nuclear and mitochondrial DNA (Haag et al. 1998). These four genes (HBX, AgB-1, Act II, ND-1) have been previously described and validated for similar purposes (Table 2).

PCR was performed with $100 \mu \mathrm{M}$ of each dNTP, $12.5 \mu \mathrm{M}$ of each primer and $1 \mathrm{U}$ of Taq DNA polymerase (Amplitaq, Perkin Elmer, Norwalk, Conn., USA) in a final volume of $50 \mu \mathrm{l}$. The amplification reaction was carried out in a 9700 thermocycler (GeneAmp PE Applied Biosystems) under the following conditions: a hot start $95^{\circ} \mathrm{C}$ for 5 min followed by 60 cycles of $30 \mathrm{~s}$ denaturation at $94^{\circ} \mathrm{C}, 30 \mathrm{~s}$ annealing at $55^{\circ} \mathrm{C}$, $30 \mathrm{~s}$ extension at $72^{\circ} \mathrm{C}$ followed by a final extension of $10 \mathrm{~min}$ at $72^{\circ} \mathrm{C}$.

The corresponding amplicons were checked on a $1.5 \%$ agarose gel and automatically sequenced using the same primers as for the primary amplification of PCR products by fluorescence labelling with a model $3730 \mathrm{ABI}$ prism system. DNA sequence comparison was achieved by using GenBank (http://www.ncbi.nlm.nih.gov/ BLAST/blast_databases.html) with the BLAST system.

\section{Results}

PCR and subsequent sequencing findings involving isolates obtained from the 20 intermediate and four definitive hosts (Table 1) are shown in Table 3. Sequencing yielded $100 \%$ homology to the reference ovine strain for all genes tested. When mitochondrial $N D-1$ sequences were aligned, six pig isolate sequences, basically corresponding to the $G 1$ genotype, showed a minor variation by differing in one out of 141 nucleotides (Fig. 1; GenBank accession number: AY461433). This nucleotide substitution leads to an amino acid change with an arginine being substituted by a serine. These nucleotide differences are not due to mistakes in incorporation by Taq DNA-polymerase, as they occurred at the same sites in several independent DNA extractions and repeated PCR reactions. Moreover, the same substitution was identical in all six pig isolates.

\section{Discussion}

Most studies on strain variability in E. granulosus have been based on genes originating from the mitochondrial 
Table 2 Primer description, genes targets and references

\begin{tabular}{|c|c|c|c|c|}
\hline Target & Genomic region & Sequence & $\begin{array}{l}\text { Amplicon } \\
\text { in bp }\end{array}$ & Reference \\
\hline$A C T I I$ & Non coding nuclear & $\begin{array}{l}5^{\prime} \text { GTCTTCCCCTCTATCGTGGG 3' } \\
5^{\prime} \text { CTAATGAAATTAGTGCTTGTGCGC 3' }\end{array}$ & 268 & Silva et al. (1993) \\
\hline$N D-1$ & Coding mitochondrial & $\begin{array}{l}5^{\prime} \text { TTCTAGGTATTCTTTGTTGTG } 3^{\prime} \\
5^{\prime} \text { CAAGCTTCATCAACAACTATAA } 3^{\prime}\end{array}$ & 141 & Bowles and McManus (1993) \\
\hline$H b x 2$ & Non coding mitochondrial & $\begin{array}{l}5^{\prime} \text { TTCTCCTCTAGCCAGGTCCA } 3^{\prime} \\
5^{\prime} \text { TATAGCGCCGATTCTGGAAC } 3^{\prime}\end{array}$ & 330 & Haag et al. (1998) \\
\hline
\end{tabular}

Table 3 Bulgarian isolates of E. granulosus analysed by sequencing and comparison of their genotype identity

\begin{tabular}{llc}
\hline Host & \multicolumn{2}{l}{ Genotype (isolate code) } \\
\hline Cattle & $G 1$ & $\left(1 \mathrm{C}-8 \mathrm{C}\right.$, identical sequence for all four genes $\left.{ }^{\mathrm{a}}\right)$ \\
Sheep & $G 1$ & $(1 \mathrm{~S}-6 \mathrm{~S}$, identical sequence for all four genes) \\
Pig & $G 1^{\mathrm{b}}$ & $\left(1 \mathrm{P}-6 \mathrm{P}\right.$, identical sequence for three genes $\left.{ }^{\mathrm{b}}\right)$ \\
Jackal & $G 1$ & $(\mathrm{~J} 1-\mathrm{J} 3$, identical sequence for all four genes $)$ \\
Wolf & $G 1$ & $(\mathrm{~W} 1$, identical sequence for all four genes $)$
\end{tabular}

${ }^{\mathrm{a}} H B X, A g B-1$, Act $I I, N D-1$

${ }^{\mathrm{b}}$ Microvariant for $N D-1$
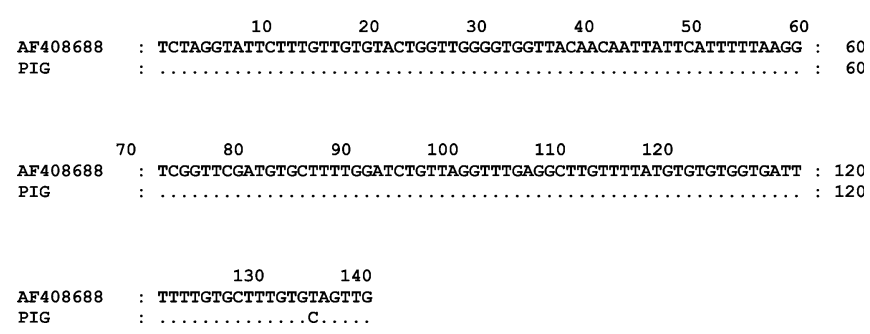

Fig. 1 Nucleotide sequence of the fragment of $N D-1$ showing the region with the microvariant (GenBank accession no. AY461433) in the pig isolate at position 376 aligned with the published reference sequence (EMBL/GenBank accession no. AF408688). A dot indicates a nucleotide that is conserved relative to the published G1 sequence

genome. To increase the probability that such analyses accurately reflect the true evolutionary pathway of the strains involved, sequences from a number of other genes that have evolved independently are required (Pamilo and Nei 1988). This study describes a genetic variability analysis of representative genomic locations of E. granulosus in Bulgaria. The genes chosen for this analysis covered a representative selection of the parasite genome including coding or intron regions of the mitochondrial and nuclear genome.

The results showed that all samples provided (for $H B X, A C T I I$ and $A g B-1) 100 \%$ identity with the $G 1$ genotype (ovine), thus demonstrating that the sheep strain appears to be the dominant one in Bulgaria. As this G1 genotype also appears in other host species, transmission to e.g. pigs and cattle - as already reported in other parts of Europe ( Eckert et al.1993; Scott et al.1997; Kedra et al.1999; Snabel et al. 2000) -also seems likely in Bulgaria. The sheep strain has always been considered the major source of human infection (Thompson et al. 1995; Eckert et al. 2000), and we hope to perform future analyses with parasite material of human origin to confirm this hypothesis.

For the $N D-1$ gene (subunit 1 of NADH dehydrogenase I), $100 \%$ identity to the $G 1$ genotype was observed for cattle, jackal, wolf and sheep isolates; the six pig isolates, however, exhibited a transversion ( $\mathrm{T}: \mathrm{A} \rightarrow$ G:C) at position 376 (Fig. 1).

It became apparent that these nucleotide differences were not due to mistakes in incorporation by Taq DNApolymerase as they occurred at the same site in several independent DNA extractions and repeated PCR reactions. Moreover, the same substitution was identical in all of the six pig isolates. All pig isolates originated from the same area as the other isolates (wider Stara Zagora region). Thus, a geographical explanation with disparately evolving isolates is not likely.

The presence of a single genotype within a relatively large spectrum of wildlife and domestic animals in Bulgaria indicates the presence of a dominant transmission cycle involving additional host species. Based on these findings, it will be interesting to carry out additional studies on the prevalence in domestic definitive hosts such as the dog, as well as the human population. Confirming the presence of a single genotype in humans will help us tackle the transmission and exposure risks in humans, and thus to elaborate appropriate measures of control and prevention of CE in Bulgaria.

Acknowledgements This work was supported by the Swiss National Science Foundation (SCOPES No. 7IP062584 and research grant no. 31-63615.00) and the EU EchinoRisk-project QLK2-CT-200101995 (BBW no. 00.0586-1).

\section{References}

Bowles J, McManus DP (1993) Rapid discrimination of Echinococcus species and strains using a polymerase chain reactionbased RFLP method. Mol Biochem Parasitol 57:231-240

Bowles J, Blair D, McManus DP (1992) Genetic variants within the genus Echinococcus identified by mitochondrial DNA sequencing. Mol Biochem Parasitol 54:165-173

Bowles J, Blair D, McManus DP (1994) Molecular genetic characterization of the cervid strain ('northern form') of Echinococcus granulosus. Parasitology 109:215-221 
Eckert J, Thompson RCA, Lymbery D, Pawlowski ZS, Gottstein B, Morgan UM (1993) Further evidence for the occurrence of a distinct strain of Echinococcus granulosus in European pigs. Parasitol Res 79:42-48

Eckert J, Conraths FJ, Tackmann K (2000) Echinococcosis: an emerging or re-emerging zoonosis? Int J Parasitol 30:1283-1294

Frosch P, Hartmann M, Mühleschlegel F, Frosch M (1994) Sequence heterogeneity of the echinococcal antigen B. Mol Biochem Parasitol 64:171-175

Georgieva D, Ivanov A, Prelezov P (1999a) Studies on the parasitic fauna in stray dogs in the Stara Zagora region. Bulg J Vet Med $2: 121-124$

Georgieva D, Prelezov P, Koinarski V (1999b) Parasitological study of soil and sand samples from different regions of Stara Zagora region. Bulg J Vet Med 2:125-129

Haag KL, Araújo AM, Gottstein B, Siles-Lucas M, Thompson RCA, Zaha A (1998) Breeding systems in Echinococcus granulosus (Cestoda, Taeniidae): selfing or outcrossing. Parasitology $118: 63-71$

Kedra AH, Swiderski Z, Tkach VV, Dubinsky P, Pawlowski Z, Stefaniak J, Pawlowski J (1999) Genetic analysis of Echinococcus granulosus from human and pigs in Poland, Slovakia and Ukraine. A multicentre study. Acta Parasitol 44:248-254

Lavikainen A, Lehtinen MJ, Meri T, Hirvela-Koski V, Meri S (2003) Molecular genetic characterization of the Fennoscandian cervid strain, a new genotypic group (G10) of Echinococcus granulosus. Parasitology 127:207-215

Lymbery AJ (1992) Interbreeding, monophyly and the genetic yardstick: species concepts in parasites. Parasitol Today 8:208211

McManus DP, Bowles J (1996) Molecular genetic approaches to parasite identification: their value in diagnostic parasitology and systematics. Int J Parasitol 26:687-704
McManus DP, Ding Z, Bowles J (1994) A molecular genetic survey indicates the presence of a single, homogeneous strain of Echinococcus granulosus in north-western China. Acta Trop 56:7-14

McManus DP, Donald P, Zhang W, Li J, Bartley PB (2003) Echinococcosis. Lancet 362:1295-1304

Pamilo P, Nei M (1988) Relationships between gene trees and species trees. Mol Biol 5:568-583

Reddy YA, Rao JR, Butchaiah G, Sharma B (1998) Random amplified polymorphic DNA for the specific detection of bubaline Echinococcus granulosus by hybridization assay. Vet Parasitol 79:315-323

Scott JC, Stefaniak J, Pawlowski ZS, McManus DP (1997) Molecular genetic analysis of human cystic hydatid cases from Poland: identification of a new genotypic group (G9) of Echinococcus granulosus. Parasitology 114:37-43

Silva CMD, Ferriera HB, Picon M, Gorfinkel N, Ehrlich R, Zaha A (1993) Molecular cloning and characterization of actin genes from Echinococcus granulosus. Mol Biochem Parasitol 60:209220

Snabel V, D'Amelio S, Mathiopoulos K, Turcekova L, Dubinsky P (2000) Molecular evidence for the presence of a G7 genotype of Echinococcus granulosus in Slovakia. J Helminthol 74:177-181

Thompson RCA, Lymbery AJ (1988) The nature, extent and significance of variation within the genus Echinococcus. Adv Parasitol 27:209-259

Thompson RCA, Lymbery AJ, Constantine CC (1995) Variation in Echinococcus: towards a taxonomic revision of the genus. Adv Parasitol 35:145-176

Todorov T, Boeva V (1999) Human echinococcosis in Bulgaria: a comparative epidemiological analysis. Bull World Health Organ 77:110-118 